Original Article

\title{
FORMULATION OPTIMIZATION AND CHARACTERIZATION OF AQUEOUS INJECTION CONTAINING POORLY SOLUBLE DRUG USING MIXED HYDROTROPIC SOLUBILIZATION
}

\author{
NEELKUMAR K. DARAJI ${ }^{1}$, VIPUL P. PATEL ${ }^{2 *}$, VINODKUMAR D. RAMANI ${ }^{3}$
}

1Pharmacy Department, Hemchandracharya North Gujarat University, Patan, Gujarat, India, ${ }^{2}$ Sanjivani College of Pharmaceutical Education and Research, Kopargaon, Maharashtra, India, ${ }^{3}$ Bhagwan Mahavir College of Pharmacy, Bhagwan Mahavir University, Surat, Gujarat, India

Email: v_pharmacy@yahoo.co.in

Received: 04 May 2021, Revised and Accepted: 02 Jul 2021

\begin{abstract}
Objective: Mefenamic acid (MFA) is an NSAID that exhibits anti-inflammatory analgesic and antipyretic activity. Peak plasma levels are attained in 2-4 $\mathrm{h}$ and the elimination half-life approximates $2 \mathrm{~h}$, repetitive administration of tablets for 3-5 times a day is desired. It is supplied only in the form of tablets for oral administration. In acute conditions drug administered parenterally could give rapid relief from severe symptoms like pain. Thus, formulation of injectable formulation of MFA could be better alternative compared to conventional tablet dosage form. The low aqueous solubility of MFA precludes its use in parenteral formulation development.
\end{abstract}

Methods: In this work attempt were made to enhance the aqueous solubility of mefenamic acid using mixed solvency technique. For that different hydrotropic agents such as Urea, Sodium acetate, sodium benzoate, sodium citrate and their blends were evaluated. Optimal concentration of hydrotropic agent in blend was determined using D-optimal mixture experimental design. The optimized bled was used to develop the aqueous injection of mefenamic acid. The developed injection was subjected for various quality control tests and stability of developed formulation was also evaluated.

Results: The aqueous solubility in optimized blend of hydrotropic agent batches (U: SA: SB: SC, 4:4:23:9 \%w/v) showed 835.71-fold compared to MFA solubility in distilled water. The quality control tests for parenteral formulation and accelerated stability study were found to be within prescribed limits and stable.

Conclusion: The inadequate solubility of MFA was overcome, and aqueous injection was successfully developed which can be serve as cost effective treatment in various indications.

Keywords: Mixed solvency, Mefenamic acid, Solubility, Aqueous injection, Hydrotropy, Hydrotrops

(c) 2021 The Authors. Published by Innovare Academic Sciences Pvt Ltd. This is an open access article under the CC BY license (https://creativecommons.org/licenses/by/4.0/) DOI: https://dx.doi.org/10.22159/ijcpr.2021v13i5.1908 Journal homepage: https://innovareacademics.in/journals/index.php/ijcpr

\section{INTRODUCTION}

For poorly soluble drugs usually, dissolution becomes the decisive factor for its poor bioavailability which again can limit their therapeutic effectiveness [1]. Mefenamic acid (MFA) is an NSAID that exhibits anti-inflammatory analgesic and antipyretic activity. Peak plasma levels are attained in 2 to $4 \mathrm{~h}$ and the elimination halflife approximates $2 \mathrm{~h}$, repetitive administration of tablets for 3-5 times a day (depending upon severity of pain) is desired. Also, the active site of absorption for mefenamic acid is stomach and upper part of small intestine. So, once emptied from stomach the passage through the small intestine is rapid, thus limiting the extent of absorption.

It is supplied only in the form of tablets and capsules for oral administration. Mefenamic acid is practically insoluble in water $(0.004 \mathrm{mg} / \mathrm{ml})[2,3]$ which precludes its use in parenteral and oral solutions. Moreover, a drug administered parenterally is immediately available in systemic circulation and it is rapid as well as more effective in treatment of acute conditions like severe pain during excessively heavy periods caused by abnormal function and presence of a contraceptive coil. Due to low aqueous solubility of mefenamic acid resist the formulator to develop an aqueous intravenous injection. Therefore, aqueous solubility of mefenamic acid was need be enhanced. Solubility enhancement of insoluble drug mefenamic acid has been extensively studied to overcome difficulties that frequently come across during formulation development [4-6]. Hydrotropic agents and cosolvents have been observed to enhance the aqueous solubility of poorly water-soluble drugs [7-9]. Maheshwari et al. have demonstrated the synergistic solubilizing capability due to a mixed hydrotropy approach and this approach has been applied to enhance the solubility of various poorly soluble drug $[10,11]$.

In this present research, we have explored the application of mixed solvency technique in the formulation of aqueous injection dosage form of water-insoluble drug mefenamic acid and to reduce the concentration of individual hydrotropic agents to minimize the side effects. In hydrotropic solubilization, a high concentration of an additive is required to produce an appreciable increase in aqueous solubility of a poorly water-soluble drug. In this case, the hydrotropic agent employed to give a desirable solubility may produce its toxicity. However, if the same enhancement in solubility can be achieved by mixing, say five solubilizers (each in one-fifth concentration) then the toxic level of the five solubilizers can be reduced fivefold. In case of synergistic effect in solubility due to mixing of, say, five solubilizers (in one-fifth concentration), the toxic level of individual hydrotropes can further be lowered because still less concentration of the hydrotropic agents shall be sufficient for the desired solubility enhancement. In mixed solvency technique different hydrotropic agents, their blends were evaluated and optimized using D-optimal mixture experimental design.

\section{MATERIALS AND METHODS}

\section{Materials}

Mefenamic acid was obtained as a gift sample from Alembic Ltd., Vadodara, India. The hydrotropes like urea, sodium acetate, sodium benzoate, sodium citrate were purchased from Merk laboratories, Mumbai, India. Polyethylene glycol 400 and sodium lauryl sulfate were also procured from Merk laboratories, Mumbai, India. The other reagents and solvents were used of laboratory grade. 


\section{Methods}

Development of UV calibration curve of mefenamic acid in hydrotropic solutions

For quantification of the drug during various stages of formulation development, the UV calibration curve was developed using UV visible spectrophotometer (Shimadzu ${ }^{\circledR}$ UV-1800, Kyoto, Japan). A $10 \mathrm{mg}$ of pure drug mefenamic acid was accurately weighed and transferred into a $100 \mathrm{ml}$ volumetric flask. It was dissolved in an adequate amount of various hydrotropic solvent systems (table 3) and volume was made up to $100 \mathrm{ml}$ to obtain a stock solution of 100 $\mu \mathrm{g} / \mathrm{ml}$. From $100 \mu \mathrm{g} / \mathrm{ml}$ solution appropriate dilutions were prepared in appropriate ranges. The absorbance of resulting solutions was noted at $332 \mathrm{~nm}$ against the respective blank.

\section{Saturation solubility study}

The saturation solubility study was performed using the shake flask method. The excess amount of sample was added in $10 \mathrm{ml}$ of the solvent system (distilled water and different solutions containing varying concentrations of hydrotropic agent/s) in a $10 \mathrm{ml}$ volumetric flask. The flask was shaken for $24 \mathrm{~h}$ in wrist action shaking matching. Then, the solution was centrifuged at 3000 RPM for 5 min and then filtered through Whatman filter paper. An aliquot was suitably diluted and analyzed using UV spectrophotometer at $332 \mathrm{~nm}$.

\section{Selection of hydrotropic agent}

To identify appropriate hydrotropic agent, the solubility of mefenamic acid was determined individually in four different hydrotropic agents namely urea (U), sodium acetate (SA), sodium benzoate (SB), sodium citrate (SC) at concentration of $10 \%, 20 \%$, $30 \%$, and $40 \%$ solutions. Accurately measured $5 \mathrm{ml}$ of a particular blend of hydrotropic agent was taken in a $10 \mathrm{ml}$ volumetric flask and an excess amount of drug was added and mechanically shaken until a saturated solution was formed. The volumetric flask was shaken on wrist action shaking matching for $12 \mathrm{~h}$ so that equilibrium solubility can be achieved, and the solution was allowed to equilibrate for $24 \mathrm{~h}$. Then solution was centrifuged at $3000 \mathrm{RPM}$ for $5 \mathrm{~min}$ in ultra-centrifuge and then solution was filtered through Whatman filter. An aliquot was suitably diluted with distilled water and analyzed using UV spectrophotometer at $332 \mathrm{~nm}$.

\section{Optimization of hydrotropic mixture using D-optimal design}

The primary objective of optimization is to achieve highest solubility ( $\geq 40 \mathrm{mg} / \mathrm{ml}$ ) of $30 \%$ and $40 \%$ solutions, solubility of mefenamic acid was increasing with increasing mefenamic acid using mixture of various hydrotropic agents (mixed solvency technique). Then, to decrease the concentration of sodium benzoate, different combinations of above mentioned four hydrotropic agents in different ratios were tried to determine enhancement in saturation solubility so that the total concentration of hydrotropic agents was always $40 \% \mathrm{w} / \mathrm{v}$ (volume of aqueous phase is constant). Thus, in the present investigation, further optimization with these four identified factors (\% w/v concentration of hydrotropes) was performed using a D-optimal design. Briefly, 16 mixture batches were prepared by varying the $\% \mathrm{w} / \mathrm{v}$ concentration of hydrotropes and evaluated for saturation solubility $(\mathrm{mg} / \mathrm{ml}$ ) of mefenamic acid (table 1$)$.

Table 1: D-optimal design setup

\begin{tabular}{|c|c|c|c|}
\hline \multirow[t]{2}{*}{ Factor code } & \multirow[t]{2}{*}{ Factor name } & \multicolumn{2}{|c|}{ Factor level } \\
\hline & & Low (-1) & High (+1) \\
\hline \multicolumn{4}{|c|}{ Independent variables } \\
\hline $\mathrm{X}_{1}$ & Concentration of Urea (U) (\% w/v) & 0 & 40 \\
\hline $\mathrm{X}_{2}$ & Concentration of sodium acetate (SA) (\% w/v) & 0 & 40 \\
\hline $\mathrm{X}_{3}$ & Concentration of sodium benzoate (SB) (\% w/v) & 0 & 40 \\
\hline $\mathrm{X}_{4}$ & Concentration of sodium citrate (SC) $(\% \mathrm{w} / \mathrm{v})$ & 0 & 40 \\
\hline \multicolumn{4}{|c|}{ Dependent variable } \\
\hline $\mathrm{Y}_{1}$ & Saturation solubility of MFA & & \\
\hline Constrain: to & ation of hydrotropic agents in a blend must be $40 \% \mathrm{w} / \mathrm{v}$ & & \\
\hline
\end{tabular}

\section{Formulation of aqueous injection of mefenamic acid}

Each ampule containing $100 \mathrm{mg}$ mefenamic acid per $2.5 \mathrm{ml}$ was prepared. The proposed formulations containing the amount of solubilizers and drug that will be administered through each mixed blend is shown in table 2 . Three batches (Batch size $500 \mathrm{ml}$ ) of optimized aqueous injection formula were prepared in an aseptic area at the temperature NMT $25^{\circ} \mathrm{C}$ and $\mathrm{RH} 45 \% \pm 5 \%$. All the utensils used were sterilized. To $450 \mathrm{ml}$ of WFI, sodium citrate was added under continuous stirring, then sodium benzoate was added and stirred to get a clear solution. Then Urea and sodium acetate were added and dissolved. To this solution, mefenamic acid was added and stirred for 20 min to get a clear solution, and volume was makeup to $500 \mathrm{ml}$ using WFI. The final injection solution was filtered through a $0.45 \mu$ membrane filter using a sterilized vacuum filtration assembly. The $2.5 \mathrm{ml}$ of final product was filled in type I clear glass ampules using a syringe and sealed by pull sealing method under aseptic condition.

Table 2: Injection composition for different batches

\begin{tabular}{llll}
\hline Ingredients & Concentration (\%w/v) & \\
\cline { 2 - 4 } & MFI-OB1 & MFI-OB3 & MFI-0B5 \\
\hline Mefenamic acid & 40 & 40 & 40 \\
Urea & 5.454 & 0.106 & 4 \\
Sodium acetate & 0.092 & 2.8 & 4 \\
Sodium Benzoate & 24.396 & 23.144 & 23 \\
Sodium citrate & 9.904 & 13.849 & 9 \\
Water for injection & Up to $2.5 \mathrm{ml}$ & & \\
\hline
\end{tabular}

\section{Benchtop stability of mefenamic acid in bulk solution}

The stability of mefenamic acid in the bulk solution was studied for $24 \mathrm{~h}$ under room temperature and refrigerated conditions $\left(2\right.$ to $\left.8^{\circ} \mathrm{C}\right)$ before ampule filing. The \% drug content, presence of turbidity, and $\mathrm{pH}$ were observed for each batch (MFI-OB, MFI-OB3, and MFI-OB5).

\section{Leak test}

To detect faulty sealing of ampules leak test was performed. After applying positive and reduced pressure in the leak test apparatus, the ampules were removed and washed with distilled water, and visually inspected for color change in ampule solution. 


\section{Clarity test}

To detect visible particulate matter in sealed ampules clarity test was performed using white and black background under illuminating light.

\section{Pyrogen test (LAL test)}

The Limulus amebocyte lysate test (LAL test) was conducted to detect bacterial endotoxins in the formulation. The solution from four sealed ampules (batch MFI-OB5) was withdrawn in sterile test tubes containing LAL reagent and mixed well. Positive control spiked with control standard endotoxin (CSE) and negative control containing triple distilled water was also prepared to eliminate procedure error. The test tubes were incubated at $37^{\circ} \mathrm{C}$ for $1 \mathrm{~h}$. Then each test tube was visually inspected for turbidity and gel formation, firm gel formation indicates the presence of Pyrogen.

\section{Sterility test}

The sterility test of prepared injections was tested using direct Inoculation method. The liquid was removed from each test container (ten sample ampules) with a sterile syringe. Half of the ampule content (batch MFI-OB5) was transferred into a culture tube (containing fluid thioglycolate medium). The inoculated media was incubated for $14 \mathrm{~d}$. All the cultures were observed several times during the incubation period. If the test specimen is positive before
$14 \mathrm{~d}$ of incubation, further incubation is not necessary. If no evidence of microbial growth is found, the preparation under examination complies with the test for sterility.

\section{Dilution profile of formulated injection}

Series of dilutions were done by diluting injection of mefenamic acid (batch MFI-OB5) with different diluents like normal saline $(0.9 \%$ $\mathrm{NaCl}$ ), 5\% dextrose solution to observe the precipitation after dilution.

\section{Accelerated stability study}

The sealed ampules of the aqueous injections (batch OB-5) were inspected for color, turbidity, and $\mathrm{pH}$ of the formulation. The chemical stability of the formulation was assessed by the estimation of the percentage drug remaining in the formulation on storage at 2$8{ }^{\circ} \mathrm{C}$ in a refrigerator, room temperature, and $40 \pm 2{ }^{\circ} \mathrm{C} / 75 \pm 5 \% \mathrm{RH}$ in a humidity chamber at day 0 , day 15 and day 30 .

\section{RESULTS AND DISCUSSION}

UV calibration curve of mefenamic acid in hydrotropic solutions

The standard calibration curves for mefenamic acid were developed in the various hydrotropic solvent system to quantify the drug during different stages of formulation development. The regression equations and $\mathrm{R}^{2}$ value for all calibration curves were given in table 3 .

Table 3: Regression equations of MFA in different solvent systems

\begin{tabular}{llll}
\hline S. No. & Solvent system & Regression equation & $\mathbf{R}^{2}$ \\
\hline 1 & Only DW & $\mathrm{y}=0.0038 \mathrm{x}+0.0015$ & 0.998 \\
2 & $\mathrm{U}(20 \% \mathrm{w} / \mathrm{v})$ & $\mathrm{y}=0.0298 \mathrm{x}+0.0193$ & 0.9997 \\
3 & SA $(20 \% \mathrm{w} / \mathrm{v})$ & $\mathrm{y}=0.0255 \mathrm{x}+0.0007$ & 0.9954 \\
4 & SB $(20 \% \mathrm{w} / \mathrm{v})$ & $\mathrm{y}=0.1453 \mathrm{x}+0.0494$ & 0.9977 \\
5 & $\mathrm{SC}(20 \% \mathrm{w} / \mathrm{v})$ & $\mathrm{y}=0.0107 \mathrm{x}+0.0196$ & 0.9962 \\
6 & $\mathrm{U}(40 \% \mathrm{w} / \mathrm{v})$ & $\mathrm{y}=0.0596 \mathrm{x}+0.0673$ & 0.9995 \\
7 & $\mathrm{SA}(40 \% \mathrm{w} / \mathrm{v})$ & $\mathrm{y}=0.0787 \mathrm{x}+0.049$ & 0.9923 \\
8 & $\mathrm{SB}(40 \% \mathrm{w} / \mathrm{v})$ & $\mathrm{y}=0.604 \mathrm{x}+0.4426$ & 0.9984 \\
9 & $\mathrm{SC}(40 \% \mathrm{w} / \mathrm{v})$ & $\mathrm{y}=0.0406 \mathrm{x}+0.0418$ & 0.9988 \\
10 & $\mathrm{U}+\mathrm{SA}(20+20 \% \mathrm{w} / \mathrm{v})$ & $\mathrm{y}=0.2047 \mathrm{x}+0.152$ & 0.9996 \\
11 & $\mathrm{U}+\mathrm{SB}(20+20 \% \mathrm{w} / \mathrm{v})$ & $\mathrm{y}=0.9034 \mathrm{x}+0.6815$ & 0.9994 \\
12 & $\mathrm{U}+\mathrm{SC}(20+20 \% \mathrm{w} / \mathrm{v})$ & $\mathrm{y}=0.2226 \mathrm{x}+0.1781$ & 0.995 \\
13 & $\mathrm{SA}+\mathrm{SB}(20+20 \% \mathrm{w} / \mathrm{v})$ & $\mathrm{y}=0.8991 \mathrm{x}+0.6678$ & 0.9998 \\
14 & $\mathrm{SA}+\mathrm{SC}(20+20 \% \mathrm{w} / \mathrm{v})$ & $\mathrm{y}=0.0573 \mathrm{x}+0.0483$ & 0.9979 \\
15 & $\mathrm{SB}+\mathrm{SC}(20+20 \% \mathrm{w} / \mathrm{v})$ & $\mathrm{y}=0.9769 \mathrm{x}+0.7456$ & 0.9996 \\
16 & $\mathrm{U}+\mathrm{SA}+\mathrm{SB}+\mathrm{SC}(8+8+8+8 \% \mathrm{w} / \mathrm{v})$ & $\mathrm{y}=0.4175 \mathrm{x}+0.3185$ & \\
\hline
\end{tabular}

Where, $\mathrm{DW}=$ Distilled water, $\mathrm{U}=$ urea, $\mathrm{SA}=$ sodium acetate $\mathrm{SB}=$ sodium benzoate, $\mathrm{SC}=$ sodium citrate

\section{Selection of hydrotropic agent}

Saturation solubility of MFA in different concentration of hydrotropic agents was performed and results were reported in table 4. From the results it was concluded that saturation solubility (SS) of mefenamic acid was increasing with increasing concentrations of hydrotropic agents, for example, solubility in $40 \%$ urea solution was found to be much higher than solubility in $10 \%$ $20 \%$, or $30 \%$ urea solutions. The highest solubility was obtained in $40 \%$ sodium benzoate solution. Then, in order to decrease the concentration of sodium benzoate, different combinations of above mentioned 4 hydrotropic agents in different ratios were tried to determine enhancement in solubility so that the total concentration of hydrotropic agents was always $40 \% \mathrm{w} / \mathrm{v}$.

Table 4: MFA solubility in different concentration of hydrotrops

\begin{tabular}{|c|c|c|c|c|c|c|c|c|}
\hline \multirow{2}{*}{$\begin{array}{l}\text { Hydro-tropic } \\
\text { agents }\end{array}$} & \multicolumn{4}{|c|}{ Saturation solubility of MFA (mg/ml) (mean \pm SD) } & \multicolumn{4}{|c|}{ Solubility enhancement (times or fold) } \\
\hline & $10 \%$ & $20 \%$ & $30 \%$ & $40 \%$ & $10 \%$ & $20 \%$ & $30 \%$ & $40 \%$ \\
\hline Only DW & $0.0049 \pm 0.0004$ & & & & 1 & & & \\
\hline $\mathrm{U}$ & $0.884 \pm 0.014$ & $1.240 \pm 0.083$ & $1.728 \pm 0.132$ & $2.520 \pm 0.289$ & 18.038 & 25.308 & 35.269 & 51.423 \\
\hline SA & $0.172 \pm 0.018$ & $1.029 \pm 0.047$ & $1.873 \pm 0.113$ & $3.153 \pm 0.154$ & 3.500 & 21.000 & 38.231 & 64.346 \\
\hline SB & $1.623 \pm 0.075$ & $5.620 \pm 0.458$ & $12.950 \pm 0.604$ & $24.709 \pm 1.258$ & 33.115 & 114.692 & 264.385 & 504.269 \\
\hline SC & $0.198 \pm 0.007$ & $0.449 \pm 0.012$ & $0.792 \pm 0.078$ & $1.702 \pm 0.288$ & 4.038 & 9.154 & 16.154 & 34.731 \\
\hline
\end{tabular}

Where, $\mathrm{DW}=$ Distilled water, $\mathrm{U}=$ urea, $\mathrm{SA}=$ sodium acetate, $\mathrm{SB}=$ sodium benzoate, $\mathrm{SC}=$ sodium citrate, $\mathrm{n}=3$ for $\mathrm{SD}$ 


\section{Statistical analysis of D-optimal design}

Sixteen batches were prepared by using a D-optimal experimental design, varying four independent variables, $\% \mathrm{w} / \mathrm{v}$ concentration of
$\mathrm{X}_{1}=$ urea $(\mathrm{U}), \mathrm{X}_{2}=$ sodium acetate $(\mathrm{SA}), \mathrm{X}_{3}=$ sodium benzoate $(\mathrm{SB})$, $\mathrm{X}_{4}=$ sodium citrate (SC) as shown in table 5 . All batches were evaluated for saturation solubility of mefenamic acid (Y). Results are recorded in table 5 .

Table 5: D-optimal design layout with responses

\begin{tabular}{|c|c|c|c|c|c|c|c|c|c|}
\hline \multirow{4}{*}{$\begin{array}{l}\text { Batch } \\
\text { No. }\end{array}$} & \multicolumn{8}{|c|}{ Independent variables } & \multirow{3}{*}{$\begin{array}{l}\text { Dependent variable } \\
\text { SS }(\mathrm{mg} / \mathrm{ml}) \\
\text { SS }\end{array}$} \\
\hline & \multicolumn{4}{|c|}{ Coded value } & \multicolumn{4}{|c|}{ Actual value (\%w/v) } & \\
\hline & $\mathbf{U}$ & SA & SB & SC & $\mathbf{U}$ & SA & SB & SC & \\
\hline & $X_{1}$ & $\mathbf{X}_{2}$ & $\mathbf{X}_{3}$ & $\mathbf{X}_{4}$ & $\mathbf{X}_{1}$ & $\mathbf{X}_{2}$ & $\mathbf{X}_{3}$ & $\mathbf{X}_{4}$ & $\mathbf{Y}$ \\
\hline 1 & -1 & -1 & -1 & -1 & 0 & 0 & 0 & 0 & 0.05 \\
\hline 2 & 0 & -1 & -1 & -1 & 20 & 0 & 0 & 0 & 1.24 \\
\hline 3 & +1 & -1 & -1 & -1 & 40 & 0 & 0 & 0 & 2.52 \\
\hline 4 & -1 & 0 & -1 & -1 & 0 & 20 & 0 & 0 & 1.03 \\
\hline 5 & 0 & 0 & -1 & -1 & 20 & 20 & 0 & 0 & 8.47 \\
\hline 6 & -1 & +1 & -1 & -1 & 0 & 40 & 0 & 0 & 3.15 \\
\hline 7 & -1 & -1 & 0 & -1 & 0 & 0 & 20 & 0 & 5.62 \\
\hline 8 & 0 & -1 & 0 & -1 & 20 & 0 & 20 & 0 & 37.43 \\
\hline 9 & -1 & 0 & 0 & -1 & 0 & 20 & 20 & 0 & 36.98 \\
\hline 10 & -1 & -1 & +1 & -1 & 0 & 0 & 40 & 0 & 24.71 \\
\hline 11 & $1 / 5$ & $1 / 5$ & $1 / 5$ & $1 / 5$ & 8 & 8 & 8 & 8 & 17.38 \\
\hline 12 & -1 & -1 & -1 & 0 & 0 & 0 & 0 & 20 & 0.45 \\
\hline 13 & 0 & -1 & -1 & 0 & 20 & 0 & 0 & 20 & 9.42 \\
\hline 14 & -1 & 0 & -1 & 0 & 0 & 20 & 0 & 20 & 2.39 \\
\hline 15 & -1 & -1 & 0 & 0 & 0 & 0 & 20 & 20 & 41.02 \\
\hline 16 & -1 & -1 & -1 & +1 & 0 & 0 & 0 & 40 & 1.70 \\
\hline
\end{tabular}

$\mathrm{U}=$ urea, $\mathrm{SA}=$ sodium acetate $\mathrm{SB}=$ sodium benzoate, $\mathrm{SC}=$ sodium citrate, $\mathrm{SS}=$ Saturation Solubility

Mathematical modeling was carried out as per Equation 1 to obtain a quadratic polynomial equation (full model) which describes the relationship of the dependent variable $\mathrm{Y}$ with $\mathrm{X}_{1}, \mathrm{X}_{2}, \mathrm{X}_{3}$, and $\mathrm{X}_{4}$ [12] Full model Equation 1 for Saturation solubility described as bellow:

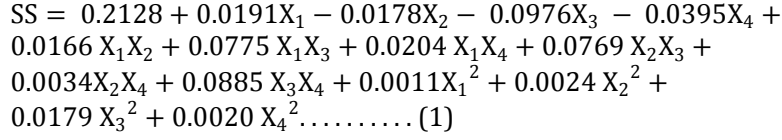

The SS (dependent variables) obtained at various levels of four independent variables $\left(\mathrm{X}_{1}, \mathrm{X}_{2}, \mathrm{X}_{3}\right.$, and $\left.\mathrm{X}_{4}\right)$ were subjected to multiple regression to yield a quadratic polynomial equation (full model). The main effects of $X_{1}, X_{2}, X_{3}$, and $X_{4}$ represent the average result of changing one variable at a time from its low to high value. The interactions $\left(\mathrm{X}_{1} \mathrm{X}_{2}, \mathrm{X}_{1} \mathrm{X}_{3}, \mathrm{X}_{1} \mathrm{X}_{4}, \mathrm{X}_{2} \mathrm{X}_{3}, \mathrm{X}_{2} \mathrm{X}_{4}\right.$ and $\left.\mathrm{X}_{3} \mathrm{X}_{4}\right)$ show how the dependent variable changes when two or more independent variables were simultaneously changed.

A value of SS varies from 0.049 to $41.021 \mathrm{mg} / \mathrm{ml}$ among sixteen batches. This is reflected by the wide range of coefficients of the terms in Equation 1. Small values of coefficients $(p>0.01)$ are regarded as least contributing and non-significant in the optimization process. By omitting non-significant terms from the full model, reduced model equations for SS (Equation 2) as below:

$S S=-0.3393+0.074 X_{1}+0.083 X_{2}-0.062 X_{3}+0.048 X_{4}+$ $0.013 X_{1} X_{2}+0.076 X_{1} X_{3}+0.018 X_{1} X_{4}+0.074 X_{2} X_{3}+0.086 X_{3} X_{4}+$ $0.0179 X_{3}^{2} \ldots \ldots(2)$

The predicted and observed values of the response parameter are shown in fig. 1 low values of residuals implied that there was a reasonable agreement between the predicted and observed values. This indicates the suitability of the model.

The significance of each coefficient of Equation 2 was determined by Ftest and p-value which are listed in table 6 . The larger the magnitude of the $F$ value and smaller the p-value, the more significant is the corresponding coefficient [13]. In reduced quadratic model, main and interaction effect for concentration of different hydrotropic agents are significant $(p<0.05)$ thus this model can be used for prediction of saturation solubility (SS) of mefenamic acid.

Table 6: Regressions analysis for saturation solubility (y)

\begin{tabular}{|c|c|c|c|c|c|c|}
\hline \multirow{2}{*}{$\begin{array}{l}\text { Model } \\
\text { term }\end{array}$} & \multicolumn{3}{|l|}{ Full model } & \multicolumn{3}{|c|}{ Reduced model } \\
\hline & Coefficients & F-Value & p-value & Coefficients & F-value & p-value \\
\hline Model & 0.2128 & 93.496 & 0.0809 & -0.339 & 461.519 & $<0.0001$ \\
\hline $\mathrm{X}_{1}$ & 0.0191 & 42.612 & 0.0968 & 0.074 & 552.174 & $<0.0001$ \\
\hline $\mathrm{X}_{2}$ & -0.0178 & 31.272 & 0.1127 & 0.083 & 572.354 & $<0.0001$ \\
\hline $\mathrm{X}_{3}$ & -0.0976 & 230.948 & 0.0418 & -0.062 & 1194.07 & $<0.0001$ \\
\hline $\mathrm{X}_{4}$ & -0.0395 & 40.269 & 0.0995 & 0.048 & 763.355 & $<0.0001$ \\
\hline $\mathrm{X}_{1} \mathrm{X}_{2}$ & 0.0166 & 4.503 & 0.2804 & 0.013 & 30.3881 & 0.0027 \\
\hline $\mathrm{X}_{1} \mathrm{X}_{3}$ & 0.0775 & 98.536 & 0.0639 & 0.076 & 541.936 & $<0.0001$ \\
\hline $\mathrm{X}_{1} \mathrm{X}_{4}$ & 0.0204 & 6.829 & 0.2327 & 0.018 & 51.8421 & 0.0008 \\
\hline $\mathrm{X}_{2} \mathrm{X}_{3}$ & 0.0769 & 97.023 & 0.0644 & 0.074 & 530.008 & $<0.0001$ \\
\hline $\mathrm{X}_{2} \mathrm{X}_{4}$ & 0.0034 & 0.185 & 0.7414 & - & - & - \\
\hline $\mathrm{X}_{3} \mathrm{X}_{4}$ & 0.0885 & 128.361 & 0.0560 & 0.086 & 712.599 & $<0.0001$ \\
\hline $\mathrm{X}_{1}^{2}$ & 0.0011 & 0.051 & 0.8585 & - & - & - \\
\hline $\mathrm{X}_{2}{ }^{2}$ & 0.0024 & 0.255 & 0.7021 & - & - & - \\
\hline $\mathrm{X}_{3}{ }^{2}$ & 0.0179 & 14.300 & 0.1646 & 0.017 & 49.7446 & 0.0009 \\
\hline $\mathrm{X}_{4}{ }^{2}$ & 0.0020 & 0.183 & 0.7424 & - & - & $<0.0001$ \\
\hline
\end{tabular}

*Significant $(\mathrm{p}$ value $<0.01$ ) 


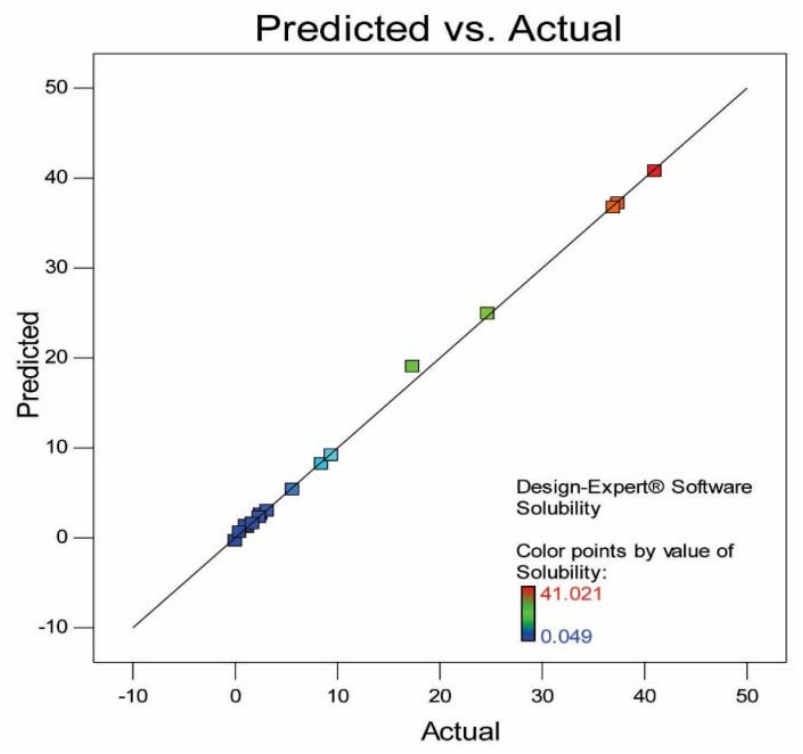

Fig. 1: Observed vs predicted values of response (ss)

\section{Validation of statistical design}

The table 7 represents ANOVA of the full model and reduced model for SS. F-statistic value obtained from the results of ANOVA confirmed omission of non-significant terms of equations. Since the calculated $\mathrm{F}$ value, as shown in table 7 , was less than the tabled $\mathrm{F}$ value for saturation solubility (SS), it was concluded that the neglected terms do not significantly contribute to the prediction, and hence reduced model can be applied.

For Equations 2, a sign of the coefficients explains the nature of the effect while magnitudes determine extent of effect for variables. Among the four independent variables value of coefficient of $X_{3} X_{4}, X_{2}$, $X_{1} X_{3}, X_{1}$, and $X_{2} X_{3}$ was found to be maximum in equation 3 . This reveals that $\mathrm{X}_{3} \mathrm{X}_{4}, \mathrm{X}_{2}, \mathrm{X}_{1} \mathrm{X}_{3}, \mathrm{X}_{1}$, and $\mathrm{X}_{2} \mathrm{X}_{3}$ was major contributing variable for saturation solubility of mefenamic acid (SS). The goodness of fit of the model was checked by the determination coefficient $\left(\mathrm{R}^{2}\right)$. For SS, the values of the determination coefficients $\left(\mathrm{R}^{2}=0.9992\right.$ for full model and 0.9989 for reduced model) indicated that over $99 \%$ of the total variations are explained by the model. The values of adjusted determination coefficients (SS: adjusted $\mathrm{R}^{2}=0.9885$ for full model and 0.9967 for reduced model, are also very high which indicates a high significance of the model. All the above considerations indicate excellent adequacy of the regression model and it can be used for the optimization of dependent variable SS $[14,15]$.

Table 7: ANOVA for full and reduced model

\begin{tabular}{|c|c|c|c|c|c|c|c|c|}
\hline Particulars & Model type & SS & DF & MS & F-value & P-value & $\mathbf{R}^{2}$ & F-statistic \\
\hline \multirow[t]{2}{*}{ Regression } & FM & 3239.515 & 14 & 231.39 & 93.496 & 0.081 & 0.9992 & $\mathrm{~F}_{\mathrm{cal}}=0.36$ \\
\hline & RM & 3238.481 & 10 & 323.84 & 461.519 & $9.01 \times 10^{-}[07]^{*}$ & 0.9989 & $\mathrm{~F}_{\mathrm{tab}}=2.60$ \\
\hline \multirow[t]{2}{*}{ Error } & FM & 2.47491 & 1 & 2.4749 & - & - & - & $(\alpha=0.05)$ \\
\hline & RM & 3.50850 & 5 & 0.7017 & - & - & - & \\
\hline
\end{tabular}

*Significant (p value<0.05). Where DF, Degree of freedom; FM, full model; F, Fischer ratio; MS, Mean squares; RM, reduced model; SS, Sum of squares

\section{Optimization and checkpoint analysis}

One can conclude the mathematical model itself if only the main terms are significant. Direct interpretation of equation 2 may lead to errors since interaction and polynomial terms are also significant. Therefore, contour plots and response surface plots were drawn (fig. 2). A nonlinear relationship is visible in all the plots fig. 2. Design space can be identified based on the highest and the lowest range of SS set by the user. The desirability function approach was used to search for the optimized mixture composition with desired responses. Selection from suggested mixture composition was done based on ease of mixture phase preparation and maximum saturation solubility of mefenamic acid was desired. Validation was performed by checkpoint analysis. For that, four selected mixture compositions were used to analyze the saturation solubility experimentally.

The simulated results were validated experimentally by checkpoint analysis (table 8) and it was found that the saturation solubility of mefenamic acid has less than $10 \%$ Bias between experimentally and predicted results, thereby demonstrating the suitability of the proposed modeling approach and it can enable an efficient and thorough establishment of an optimal mixture formulation using different hydrotropic agents. Checkpoint batch OB-1 (U: SA: SB: SC, 5.454:0.092:24.396:9.904 \%w/v), OB-3 (U: SA: SB: SC, 0.106:2.800:23.144:13.849 \% w/v) and OB-5 (U: SA: SB: SC, 4:4:23:9 $\% \mathrm{w} / \mathrm{v}$ ) were selected for final formulation of mefenamic acid injection.

Table 8: Checkpoint analysis results

\begin{tabular}{|c|c|c|c|c|c|c|c|c|}
\hline \multirow{2}{*}{$\begin{array}{l}\text { Optimized } \\
\text { blend }\end{array}$} & \multicolumn{4}{|c|}{ Blend composition $(\% \mathrm{w} / \mathrm{v})$} & \multirow[t]{2}{*}{ Desirability } & \multicolumn{2}{|c|}{ Solubility of mefenamic acid (mg/ml) } & \multirow[t]{2}{*}{$\%$ Bias } \\
\hline & $\mathbf{U}$ & SA & SB & SC & & Predicted & Experimental mean \pm SD & \\
\hline OB-1* & 5.454 & 0.092 & 24.396 & 9.904 & 1.000 & 41.366 & $40.06 \pm 0.80$ & 3.15 \\
\hline OB-2 & 9.871 & 0.009 & 21.474 & 8.643 & 1.000 & 41.041 & $39.01 \pm 1.19$ & 4.94 \\
\hline OB-3* & 0.106 & 2.800 & 23.144 & 13.849 & 1.000 & 41.041 & $42.01 \pm 0.40$ & 2.36 \\
\hline OB-4 & 6.040 & 2.121 & 22.851 & 8.909 & 1.000 & 41.058 & $38.23 \pm 1.29$ & 6.88 \\
\hline OB-5* & 4 & 4 & 23 & 9 & 1.000 & 41.04 & $40.95 \pm 1.97$ & 0.23 \\
\hline
\end{tabular}

*Optimized blend selected for further formulation development of MFA injection. $\mathrm{n}=3$ for SD

\section{Benchtop stability of mefenamic acid in bulk solution}

From table 9 it can be observed that the bulk solution of formulation batch MFA-OB5 shows no signs of turbidity and there was no change in assay compared to MFA-OB1 and MFA-OB3 during $24 \mathrm{~h}$ at room temperature $\left(20-25^{\circ} \mathrm{C}\right.$ ) and refrigerator condition. In batch MFAOB1 and MFA-OB3, there were some losses of drug that may be due to precipitation of drug in given condition. Additionally, the $\mathrm{pH}$ of prepared batches was found to be 7.53, 8.47, 7.86 for MFA-0B1, MFA-OB3, and MFA-OB5 respectively. The $\mathrm{pH}$ of prepared formulation bulk solutions was found to be within range of 7.5 to 8.5 which is accepted range for intravenous injection [16, 17]. Finally, MFA-OB5 was considered for further processing of ampule filling and quality control tests. 


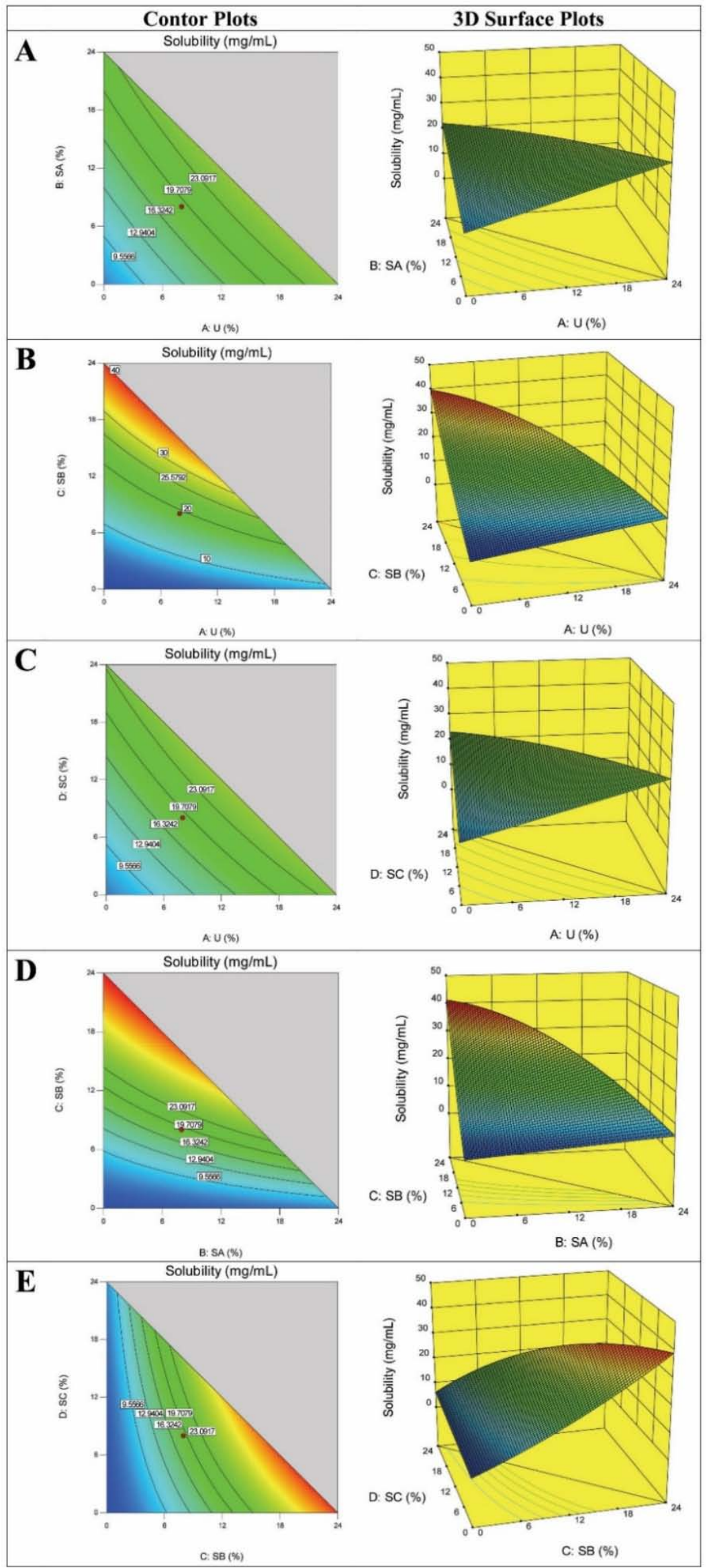

Fig. 2: Contour and 3D surface plots for saturation solubility 
Table 9: Benchtop stability of mefenamic acid in bulk solution

\begin{tabular}{|c|c|c|c|c|c|c|c|c|c|}
\hline \multirow[t]{3}{*}{ Time (h) } & \multicolumn{3}{|c|}{ MFA-0B1 } & \multicolumn{3}{|c|}{ MFA-OB3 } & \multicolumn{3}{|c|}{ MFA-OB5 } \\
\hline & \multicolumn{2}{|c|}{ Assay (\%) } & \multirow{2}{*}{$\begin{array}{l}\text { Turbidity } \\
\text { (Yes/No) }\end{array}$} & \multicolumn{2}{|c|}{ Assay (\%) } & \multirow{2}{*}{$\begin{array}{l}\text { Turbidity } \\
\text { (Yes/No) }\end{array}$} & \multicolumn{2}{|c|}{ Assay (\%) } & \multirow{2}{*}{$\begin{array}{l}\text { Turbidity } \\
\text { (Yes/No) }\end{array}$} \\
\hline & $2-8^{\circ} \mathrm{C}$ & $20-25^{\circ} \mathrm{C}$ & & $2-8^{\circ} \mathrm{C}$ & $20-25^{\circ} \mathrm{C}$ & & $2-8^{\circ} \mathrm{C}$ & $20-25^{\circ} \mathrm{C}$ & \\
\hline 0 & 100 & 100 & - & 100 & 100 & - & 100 & 100 & - \\
\hline 4 & 100 & 100 & - & 100 & 100 & - & 100 & 100 & - \\
\hline 8 & 100 & 100 & - & 99.87 & 100 & - & 100 & 100 & - \\
\hline 12 & 100 & 100 & - & 99.65 & 99.97 & + & 100 & 100 & - \\
\hline 16 & 100 & 100 & - & 98.97 & 99.85 & + & 100 & 100 & - \\
\hline 20 & 100 & 100 & -- & 98.43 & 99.23 & + & 100 & 100 & _- \\
\hline 24 & 99.98 & 100 & + & 97.93 & 98.93 & + & 100 & 100 & - \\
\hline
\end{tabular}

(+) turbidity present, (-) turbidity absent

\section{Clarity test, pyrogen test, and sterility test}

Visual inspection of prepared mefenamic injection ampules reveals no suspended particulate matters which suggests that prepared formulation is fit for further quality control tests. The Limulus amebocyte lysate test (LAL test) was conducted to detect bacterial endotoxins in formulation. Each test tube under test, positive control, and negative control were visually inspected for turbidity and gel formation. There were no signs of turbidity and firm gel formation in the sample under test and negative control tube, while in positive control tube firm gel was formed. The results indicate the absence of pyrogen in prepared formulations. Furthermore, in sterility testing inoculated media was incubated for $14 \mathrm{~d}$. All the cultures were observed several times during the incubation period.
There was no evidence of microbial growth in the specimen tube. The results suggest that the preparation under examination complies with the test for sterility.

\section{Dilution profile of formulated injection}

Series of dilutions were done by diluting injection of mefenamic acid (batch MFA-OB5) with different diluents like normal saline $0.9 \%$ $\mathrm{NaCl}$ ), 5\% dextrose solution for observing the precipitation in diluted solutions. The results shown in table 10 indicated that the formulation was stable in both dilution media. As the dilution ratio was increased, slight precipitate was observed, but after light steering, the precipitate was disappeared. This might be due to the redissolution of the precipitate.

Table 10: Dilution profile of injection formulation (batch MFA-0B5)

\begin{tabular}{|c|c|c|}
\hline \multirow{2}{*}{$\begin{array}{l}\text { Dilution ratio } \\
\text { (Formulation: Diluent) }\end{array}$} & \multicolumn{2}{|l|}{ Observation in different diluent } \\
\hline & Normal saline solution $(0.9 \% \mathrm{NaCl})$ & $5 \%$ dextrose solution \\
\hline $1: 1$ & - & - \\
\hline $1: 5$ & - & - \\
\hline $1: 10$ & - & - \\
\hline $1: 20$ & - & - \\
\hline $1: 30$ & - & - \\
\hline $1: 40$ & - & - \\
\hline $1: 50$ & - & - \\
\hline $1: 100$ & - & - \\
\hline $1: 500$ & - & - \\
\hline
\end{tabular}

(-) No precipitation, (+) Precipitation

\section{Accelerated stability study}

Results of the stability study of formulation showed that it remains unchanged in respect of $\mathrm{pH}$ and color table 11. Precipitate formation was not observed at different storage conditions, showing appreciable physical stability. The chemical stability was also noticed as there was no significant change in the assay of prepared batch at different storage conditions.

Table 11: Accelerated stability study of batch MFA-0B5

\begin{tabular}{|c|c|c|c|c|}
\hline \multirow{2}{*}{$\begin{array}{l}\text { Physical stability } \\
\text { parameter }\end{array}$} & \multirow[t]{2}{*}{ Time } & \multicolumn{3}{|l|}{ Conditions } \\
\hline & & Refrigeration $\left(2-8^{\circ} \mathrm{C}\right)$ & Room temperature & $40{ }^{\circ} \mathrm{C} / 75 \% \mathrm{RH}$ \\
\hline \multirow[t]{3}{*}{$\mathrm{pH}$} & Initial & 7.86 & 7.86 & 7.86 \\
\hline & After $15 \mathrm{~d}$ & 7.86 & 7.88 & 7.64 \\
\hline & After $30 \mathrm{~d}$ & 7.77 & 7.91 & 8.03 \\
\hline \multirow[t]{3}{*}{ Color } & Initial & Clear & Clear & Clear \\
\hline & After $15 \mathrm{~d}$ & Clear & Clear & Clear \\
\hline & After $30 \mathrm{~d}$ & Clear & Clear & Clear \\
\hline \multirow[t]{3}{*}{ Precipitation } & Initial & No ppt & No ppt & No ppt \\
\hline & After $15 \mathrm{~d}$ & No ppt & No ppt & No ppt \\
\hline & After $30 \mathrm{~d}$ & No ppt & No ppt & No ppt \\
\hline$\%$ Assay & Initial & $100.00 \pm 0.021$ & $100.00 \pm 0.021$ & $100.00 \pm 0.021$ \\
\hline \multirow[t]{2}{*}{$(n=3)$} & After $15 \mathrm{~d}$ & $99.87 \pm 0.098$ & $100.00 \pm 0.042$ & $100.00 \pm 0.041$ \\
\hline & After $30 \mathrm{~d}$ & $99.76 \pm 0.145$ & $99.98 \pm 0.045$ & $98.67 \pm 0.222$ \\
\hline
\end{tabular}




\section{CONCLUSION}

The mixed hydrotropy technique was found to be a novel, safe and effective way to enhance the solubility of poorly aqueous soluble drugs. From the present studies, it can be concluded that the problem of inadequate aqueous solubility of mefenamic acid $(0.049$ $\mathrm{mg} / \mathrm{ml}$ ) overcame using mixed hydrotropic solubilization. Using the design of experiment the hydrotropic mixture composition was optimized which shows 835.71 -fold $(40.95 \pm 1.97 \mathrm{mg} / \mathrm{ml}$ : OB-5 batch) enhancement in solubility of mefenamic acid. There are many advantages of using optimization techniques while developing a formulation because it gives the researcher the ability to study interactions between factors. It is an excellent tool for developing the best possible formulation under a given set of conditions with minimum experimentation, saving considerable time, money, and effort. Moreover, it is strongly favored by regulatory agencies because it justifies the choice of ranges and finds a robust (optimum) region and thus should be used wherever possible to obtain a product with superior quality. Moreover, the aqueous injection was successfully developed which passes all quality control tests. The developed injection formulation was also found to be stable as per the accelerated stability study. The developed formulation can be served as a cost-effective treatment in various indications for rapid relief in different clinical conditions.

\section{ACKNOWLEDGMENT}

Authors extends sincerely gratitude to Hemchandracharya North Gujarat University for providing all necessary research facility.

\section{FUNDING}

Nil

\section{AUTHORS CONTRIBUTIONS}

All the authors have contributed equally.

\section{CONFLICTS OF INTERESTS}

Authors have no conflict of interest.

\section{REFERENCES}

1. Zhou Y, Du J, Wang L, Wang Y. Nanocrystals technology for improving bioavailability of poorly soluble drugs: A minireview. J Nanosci Nanotechnol. 2017;17(1):18-28. doi: 10.1166/jnn.2017.13108, PMID 29616786.

2. Patil PB, Gupta V, Udupi R, Srikanth K, Prasad B. Development of dissolution medium for poorly water-soluble drug mefenamic acid. Res J Pharm Biol Chem. 2010;1:544-9.

3. TenHoor CN, Bakatselou V, Dressman J. Solubility of mefenamic acid under simulated fed- and fasted-state conditions. Pharm
Res. 1991;8(9):1203-5. doi: 10.1023/a:1015874906665, PMID 1788169.

4. Kumar M, Singh D, Bedi N. Mefenamic acid-loaded solid SMEDDS: an innovative aspect for dose reduction and improved pharmacodynamic profile. Ther Deliv. 2019;10(1):21-36. doi: 10.4155/tde-2018-0053, PMID 30730824.

5. Sriamornsak P, Limmatvapirat $\mathrm{S}$, Piriyaprasarth $\mathrm{S}$, Mansukmanee P, Huang Z. A new self-emulsifying formulation of mefenamic acid with enhanced drug dissolution. Asian J Pharm Sci. 2015;10(2):121-7. doi: 10.1016/j.ajps.2014.10.003.

6. Sid D, Baitiche M, Elbahri Z, Djerboua F, Boutahala M, Bouaziz $Z$, Le Borgne M. Solubility enhancement of mefenamic acid by inclusion complex with $\beta$-cyclodextrin: in silico modelling, formulation, characterisation, and in vitro studies. J Enzyme Inhib Med Chem. 2021;36(1):605-17. doi: $10.1080 / 14756366.2020 .1869225$, PMID 33557644.

7. Maheshwari R. Mixed hydrotropy in spectrophotometric analysis of aceclofenac. Indian Pharm. 2007;6:67-9.

8. Etman M, Salama R, Shamsedeen M, El-Kamel A. Solubilization of etodolac for parenteral administration. Indian J Pharm Sci. 2001;63:459.

9. Poochikian GK, Cradock JC. Enhanced chartreusin solubility by hydroxybenzoate hydrotropy. J Pharm Sci. 1979;68(6):728-32. doi: 10.1002/jps.2600680620, PMID 458574.

10. Maheshwari R. Potentiation of solvent character by mixed solvency concept: A novel concept of solubilization. J Pharm Res. 2010;3:411-3.

11. Maheshwari R, Shilpkar R. Formulation development and evaluation of injection of poorly soluble drug using mixed solvency concept. Int J Pharm Biol Sci. 2012;3.

12. Armstrong NA, James KC. Pharmaceutical experimental design and interpretation. CRC Press; 2002.

13. Adinarayana K, Ellaiah P. Response surface optimization of the critical medium components for the production of alkaline protease by a newly isolated Bacillus sp. J Pharm Pharm Sci. 2002;5(3):272-8. PMID 12553896.

14. Ahnazarova SL, Kafarov VV. Rep'ev AP. Experiment optimization in chemistry and chemical engineering. Moscow and Chicago: MIR Publishers; 1982.

15. Borror CM, Montgomery DC, Myers RH. Evaluation of statistical designs for experiments involving noise variables. J Qual Technol. 2002;34(1):54-70. doi: 10.1080/00224065. 2002. 11980129.

16. Stranz M, Kastango ES. A review of $\mathrm{pH}$ and osmolarity. Int J Pharm Compd. 2002;6(3):216-20. PMID 23979188.

17. Shi Y, Porter W, Merdan T, Li LC. Recent advances in intravenous delivery of poorly water-soluble compounds. Expert Opin Drug Deliv. 2009;6(12):1261-82. doi: 10.1517/17425240903307423, PMID 19941409. 